 \\ International Journal of Social Sciences and Management
}

\section{A Rapid Publishing Journal}

ISSN 2091-2986

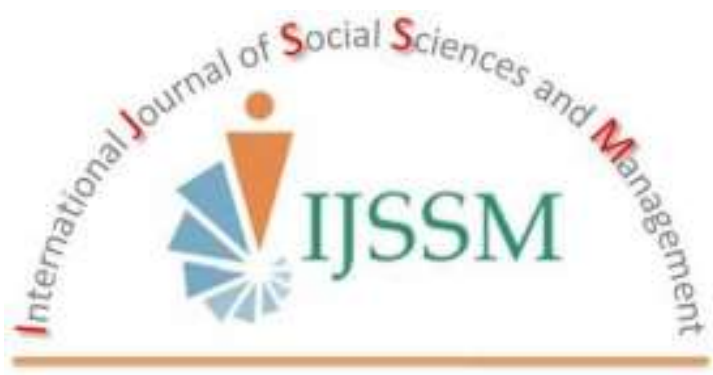

\section{Indexing and Abstracting}

CrossRef, Google Scholar, International Society of Universal Research in Sciences (EyeSource), Journal TOCs, New Jour, Scientific Indexing Services,InfoBase Index, Open Academic Journals Index (OAJI),Scholarsteer, Jour Informatics, Directory of Research Journals Indexing (DRJI), International Society for Research Activity (ISRA): Journal Impact Factor (JIF), Simon Fraser University Library, etc.

Vol- 3(1), January 2016 


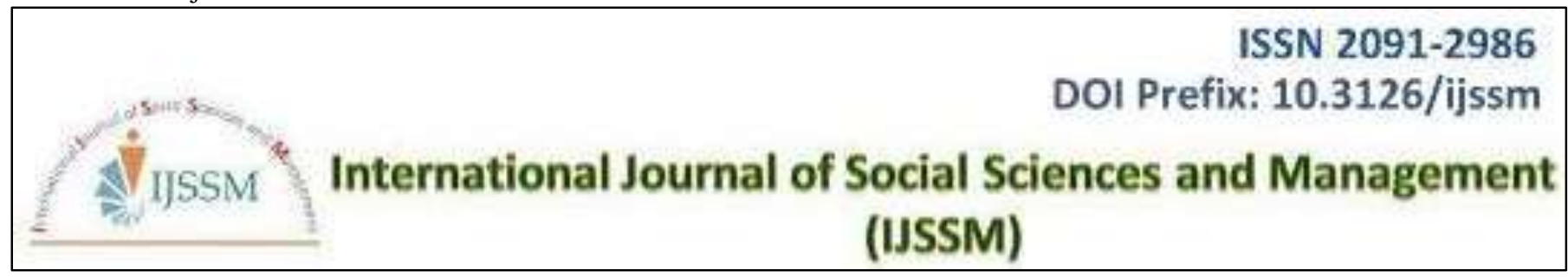

Research Article

\title{
PROGRESSION IN TOBACCO USE IN INDIA: AN APPLICATION OF SURVIVAL FUNCTION ANALYSIS
}

\author{
Shri Kant Singh ${ }^{1}$ and Gyan Chandra Kashyap ${ }^{2 *}$
}

${ }^{1}$ Department of Mathematical Demography \& Statistics, International Institute for Population Sciences, Govandi Station Road Donor Mumbai, 400088, India, Email: sksingh1992@yahoo.co.in

${ }^{2}$ International Institute for Population Sciences, Govandi Station Road Donor Mumbai, 400088, India

*Corresponding author's email: statskashyap@gmail.com

\begin{abstract}
Today India is the second largest producer of tobacco in the world and the third largest consumer. The World Health Organization predicts that tobacco deaths in India may exceed 1.5 million annually by 2020 . The purpose of the present study to evaluate the pattern and correlates of tobacco use and quitting tobacco among smokers as well as users of smokeless tobacco. This study is based on the data from the Global Adult Tobacco Survey, India (2009-10). The study used the cox's proportional hazards regression model and Kaplan-meier survival analysis for computing the probability of quitting tobacco. Three level multilevel logistic regression model have been used to carry out the pattern and correlates of tobacco use. The highest percentage of young people currently using tobacco product in the North-eastern states of India. The hazard of quitting tobacco among female is 1.35 times $(\mathrm{p}<.01)$ higher as compared to male. The chances of quitting smokeless tobacco are less in the North-East ( $\mathrm{HR}=0.484$ ) as compared to the people from North. The odds of smoking was three times higher in 45-64 age group $\left(\mathrm{OR}=3.311^{* * *}\right)$ compared to the age group of 15-24. Regional variation is the use of smokeless tobacco shows that results from the NorthEastern region $(\mathrm{OR}=8.748 * * *)$ and Eastern region $(\mathrm{OR}=8.184)$ are more likely to use smokeless tobacco in comparison to people from Northern region. This study found that the trend of use of tobacco in upward direction, whereas the probability of quitting is very low in Northeast.
\end{abstract}

Keywords: Tobacco; Smokeless tobacco; Quitting; Prevalence; Hazard

\section{Introduction}

Today India is the second largest producer of tobacco in the world and the third largest consumer. Its use and production proliferated to such an extent that, the overall 1.1 billion smokers worldwide (Bansal et at., 2005). Around 4.52 trillion cigarettes and 40.3 trillion bidis have been produced between 1910 and 2010, which are estimated to be responsible for nearly 100 million premature deaths in adult men of $\geq 35$ years (Lal et al., 2012) that numbers show the threat from the tobacco consumption. Tobacco addiction of a large number of adults has been initiated during the adolescence (Warren $e t$ at., 2000; Patel et al., 1999; Gavarasana et al., 1992; Sarma et al., 1990, Gupta et al., 1996; Colby et al., 2000). Adolescents are the most vulnerable population to initiate tobacco use. More than $40 \%$ of children had started the habit between 10-15 years of age (Chadda et al., 2002). Tobacco use by parents or an elder sibling increases the likelihood that a child begins smoking. Due to this, children are often introduced to such products at their very early life stages (Kapoor et al., 1995; Jayant et al., 1991). It is now well established that most of the adult users of tobacco start tobacco use in childhood or adolescence. It is important to understand various factors that influence and encourage young teenagers to start smoking tobacco products.

Tobacco use among adolescents in India is a matter of concern. The prevalence of tobacco use in India ranged from 14 percent among youth aged 13-15yrs to 57 percent among males aged 18-49 yrs. (Reddy et al., 2004). As per the Tobacco control in India 2004, the estimated numbers of tobacco users among those aged 10 years and above were recorded as around 250 million. (Reddy et al., 2004). The prevalence of smoking has increased mostly in low and middle income countries, while it has declined in high income countries. Therefore, it can be understand that the vast majority of deaths will occur in low income countries (Merete, 2001). The increment in prevalence in tobacco smoking among adults and women was the highest in developing countries, which now accounts for 50 percent of the global mortality and 56 percent of the disease burden. At current levels of consumption, the burden from tobacco related morbidities is estimated to double by 2020 (Shibuya et al., 2003).

Tobacco use is expected to cause approximately 8.4 million deaths, 70 percent of which will occur in developing countries by 2020 (Enis et al., 2000). Tobacco use, especially smoking is the largest cause of preventable death among adults in India (Lal et al., 2012). Nearly 900, 
000 people die every year in India due to diseases attributed to tobacco (Mamatha et al., 2014). Smoking has been widespread for many decades among men in India, where most adult deaths involve vascular disease, tuberculosis, or other respiratory diseases (Vendhan et al., 2003). The study of mortality associated with smoking in India, estimates that at least 930,000 adult deaths in India could be attributed to smoking, and that this would rise to over one million annually from 2010 (Jha et al., 2008). The existing trends in mortality, about 500 million people alive today will die prematurely as a result of tobacco use, with 1 billion deaths from tobacco expected during this century (Jha et al., 2006). The situation of tobacco consumption is grave in India where thirty percent of the population aged 15 years and above, 47 percent among men and 14 percent among women either smoke or chew tobacco.

The existing prevalence transforms to almost 195 million people in India, 154 million men and 41 million women consuming tobacco. However, this study also highlights that tobacco consumption is significantly higher among socially deprived and economically marginalized groups, especially the poor, the less educated, Scheduled castes and Scheduled tribe populations having lesser potential to use modern health care facilities. Around 15-18 percent of total deaths in India are preventable in nature as a large number of these deaths are due to tobacco related morbidity and lifestyle based diseases. Tobacco is also part of the socio-cultural setting in various societies, especially in the Eastern, Northern, and North-Eastern parts of the country. The prevalence of smoking and use of smokeless tobacco also vary widely across different states and had a strong association with an individual's socio-cultural characteristics (Rani et al., 2003).

Continuation of tobacco consumption increase the risk of cardiovascular disease and other morbidities. In a present situation in India people start tobacco use at teenage and adulthood in all the settings. That is the danger indication of burden of disease in future from the tobacco consumption. This study is focusing on age at initiation and duration of tobacco consumption, which are the important indicator to assess its harm for the health in India. Although, this paper is an attempt to find the pattern and correlates of tobacco use and quitting tobacco among smokers as well as users of smokeless tobacco.

\section{Material and Methods}

\section{Ethics statement}

The Global Ault Tobacco Survey was conducted in 200910. The Ministry of Health \& Family Welfare (MoHFW), Government of India, designated the International Institute for Population Sciences (IIPS), Mumbai, as the nodal agency for conducting GATS in India. A formal written consent was obtained and ethical issues were taken care of before interviewing the respondent in the survey.
Moreover, this study is based on anonymous public use data set with no identifiable information on the survey participants. Survey data are available upon the request on the official website of the institute at http://www.iipsindia.org.

\section{Data Source}

This study is based on the data from the Global Adult Tobacco Survey, India (GATS India). GATS India was conducted in 2009-10 as a household survey of persons in the age group 15 and above. This study used comprehensive study design for urban and rural separately. In urban areas, three-stage sampling was adopted for the selection of households. The primary sampling units (PSU) were the city wards selected using probability proportional to size (PPS) sampling from urban sampling frame. For the secondary sampling units (SSU) were census enumeration blocks (CEB) was selected by probability proportional to size (PPS) from each selected urban ward. At the third stage tertiary sampling units (TSU) were households formed the sampling frame from which a sample of required number of households was selected. In rural areas, two-stage sampling was adopted for the selection of households. The primary sampling units (PSUs) were villages and secondary sampling units (SSUs) were households. All the villages are first stratified into different strata by using geographical regions, and further stratified by village size, proportion of scheduled caste, scheduled tribe population and female literacy. At the first stage, the list of all the villages in a state/UT formed the sampling frame. The required number of villages, i.e. (PSUs), was selected according to the probability proportional to size (PPS) sampling, within each stratum. At the second stage, a list of all the residential households in each selected village formed the sampling frame from which a sample of required number of households was selected.

The data of Global Adult Tobacco Survey India (GATS India) is the global standard for systematically monitoring adult's tobacco use (smoking and smokeless) and tracking key tobacco control indicators. A national probability survey was used to provide national and regional estimates by residence and gender and state estimate by gender. Global Adult Tobacco Survey India was carried out in all 29 states of the country and the two union territories of Chandigarh and Puducherry, covering about 99.9 percent of the total population of the country. The distribution of the total sampled households $(79,690)$ was 47,959 rural and 31,731 urban. Of the total sampled households, the interview was completed in all respects in 76,069 of them, leading to an overall household response rate of 96.8 percent. A total of 46,141 rural and 29,928 urban households successfully completed their interviews, giving a rural and urban response rate of 97.4 percent and 96.0 percent respectively. A total of 69,296 interviews were 
completed among which 33,767 and 35,529 were of males and females respectively (GATS, 2009-10).

\section{Methods}

GATS survey has collected detailed information about the tobacco consumption in any form. Tobacco smoking includes manufactured cigarettes, rolled tobacco, bidis, cigars, cheroots, hukkah and smokeless tobacco includes betel quid with tobacco, khainior tobacco lime mixture, gutkha or tobacco lime, areca nut mixture, oral tobacco, pan masala and betel quid without tobacco, nasal use of snuff. We have utilized the information on the age at initiation, current use, past use, period of use and age at quitting for both tobacco smokers as well as users of smokeless tobacco. The dependent variables used in this study are current tobacco users, current tobacco smokers, current smokeless tobacco users, time variable for the duration of tobacco use and duration of use of smokeless tobacco. Independent variables used in this study are age of respondent, sex, place of residence, education, occupation, standard of living index, region, states.

\section{Statistical Analysis}

First, cross-tabulation has been used to see the state wise prevalence of current tobacco users, current tobacco smokers and current users of smokeless tobacco. Time variables were calculated from the age at initiation and age of quitting tobacco for smokers as well as users of smokeless tobacco from the reference period of time of survey. Subsequently, those who were continuing tobacco use were considered as a censored cases for this study. Cox's proportional hazards model were used to estimate the hazard ratio and their $95 \%$ confidence interval for quitting tobacco. We have used the predictor variables sex, place of residence, education, occupation and region in this model. There are several reasons for choosing Cox's proportional hazards modelling to explain the effect of covariates on time until the occurrence of event where the event is quitting tobacco. Survival analysis typically examines the relationship of the survival distribution to covariates (Hosmer et al., 1999). Kaplan-Meier survival analysis were graphed by sex, place of residence, education and region for smokers as well as users of smokeless tobacco. We evaluated the effect of age at initiation a time since quitting tobacco among the smokers and users of smokeless tobacco. An attempt has been made to find the progression of use of tobacco in all the regions of India by using the Kaplan-Meier Survival Analysis and Cox's Proportional Hazards Regression (Brenda et al., 2006; John et al., 2008).

Three level multilevel logistic regressions models are used to carry out the pattern and correlates of tobacco use. The state level and PSU level intercept variance in model 1 and model 2. The model expressed as intra-class correlation coefficients, these variances indicate that the variability in smoking and use of smokeless tobacco is associated with
between-PSU (level 2) and between state (level 3) differences. As usually the case, between-individual differences are far more important. Model 2 incorporates all explanatory variables i.e. individual, PSU and state level, into the model. We have utilized the variables age of respondent, sex, place of resident, education, occupation, standard of living index and different region of the country. All the analysis were done with the STATA 12.0 (Stata Corp LP, Texas 77845 USA).

\section{Results}

\section{Prevalence of Tobacco Use}

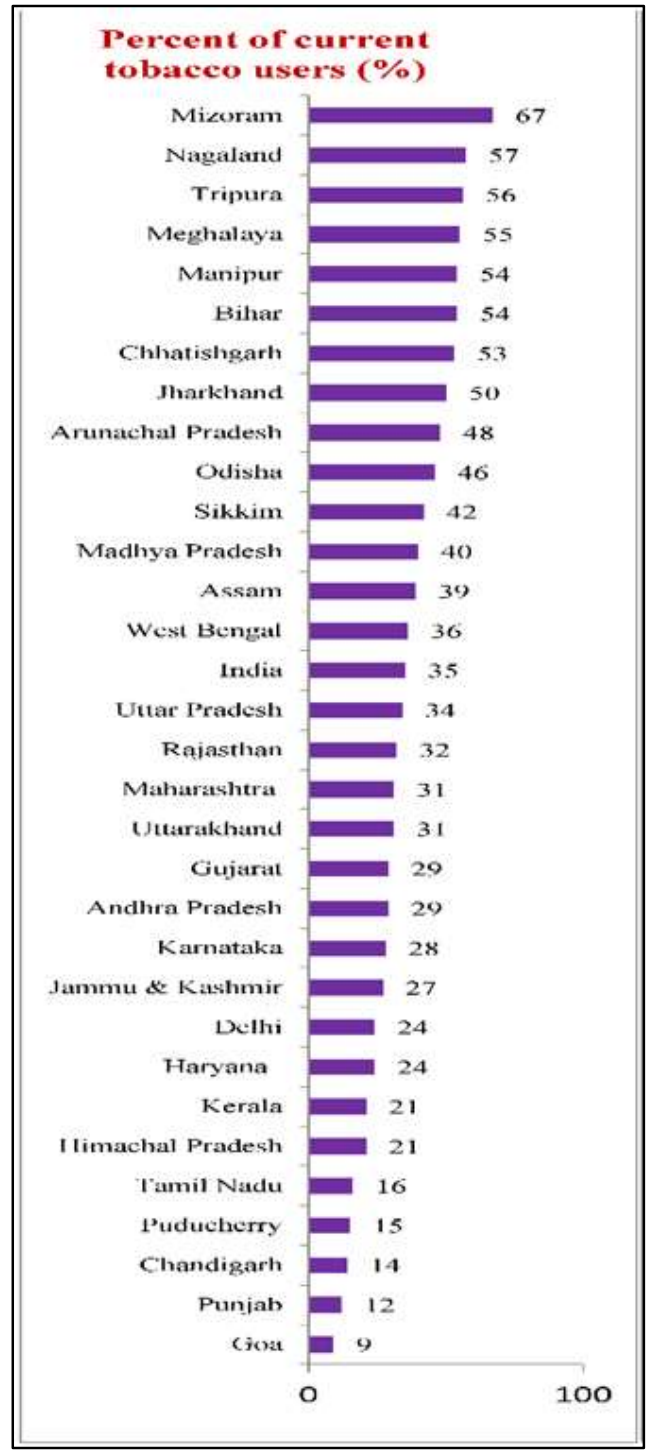

Fig. 1(a): Prevalence of tobacco users in India (GATS 2009-10).

Fig. 1(a) portrays the prevalence of the overall use of tobacco in India and its different states. The prevalence of tobacco use is the highest in Mizoram (63\%) followed by four other states from the North-Eastern region, that is, Nagaland (57\%), Tripura (56\%), Meghalaya (55\%) and Manipur (54\%). The prevalence is high in Bihar (54\%), Chhattisgarh (53\%), and Jharkhand (50\%). On the other hand, the lowest prevalence of tobacco is reported in Goa (9\%), Punjab (12\%), Chandigarh (14\%), Puducherry (15 
$\%)$ and Tamil Nadu (16\%). Fig. 1(b) presents the percentage distribution of tobacco smokers according to states and UTs. The highest prevalence of tobacco smoking is reported in Mizoram (40\%), followed by Meghalaya (36\%), Nagaland (32\%), and Arunachal Pradesh (29\%). In contrast, the lowest prevalence of tobacco smoking is reported in Goa (5\%), Maharashtra (7\%), Punjab (7\%), and Tamil Nadu (10\%), whereas the national prevalence of tobacco smoking stands at 14 percent.

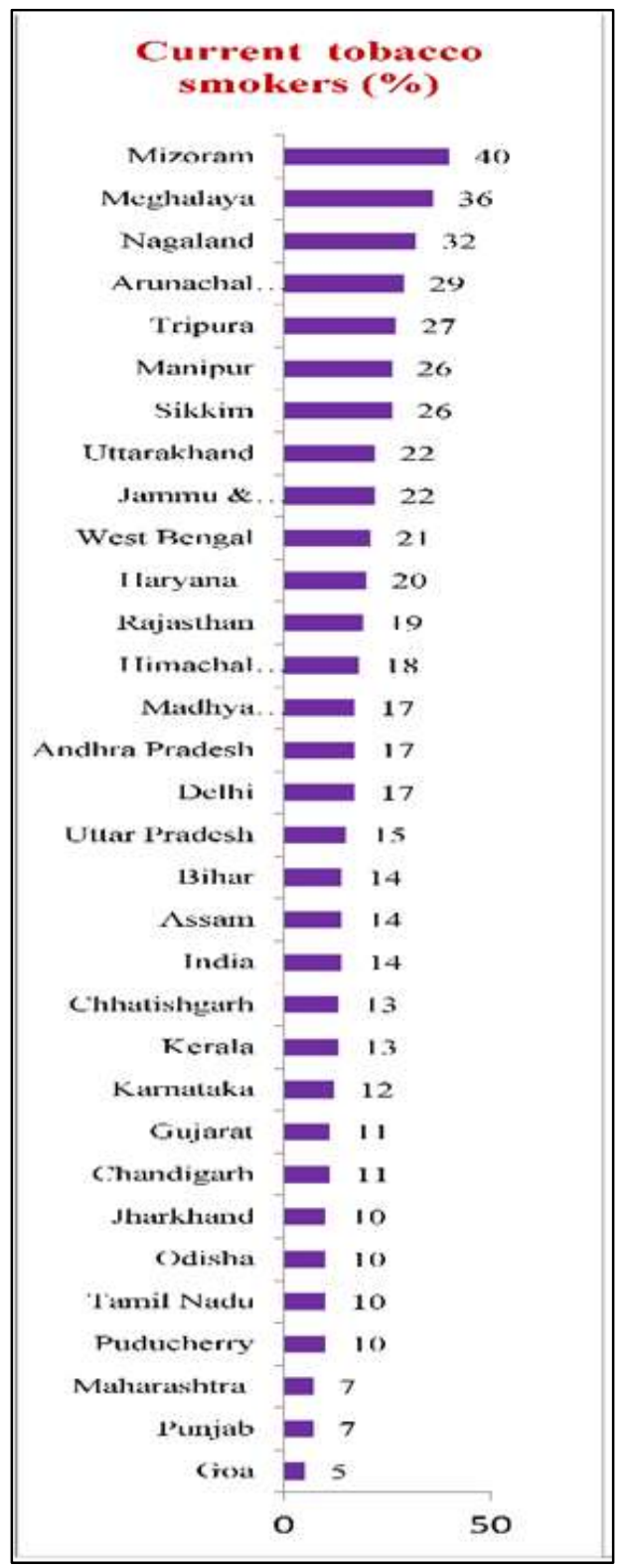

Fig. 1(b): Prevalence of tobacco smoking in India (GATS 2009-10)

Fig. 1(c) presents the percentage distribution of users of smokeless tobacco according to states and UTs in India. It is evident that there is a large variation in the prevalence of use of smokeless tobacco across different states/UTs. The highest prevalence of the use of smokeless tobacco is reported in some EAG states like Bihar (49\%), Jharkhand (48\%), Chhattisgarh (47\%) and in the North-Eastern states of Nagaland (45\%) and Manipur (45\%), while the lowest prevalence is reported by the states of Himachal Pradesh, Goa, Chandigarh (5\% in each) and Puducherry and Haryana (6\% in each), which is significantly lower than the national level prevalence of use of smokeless tobacco, that is 26 percent.

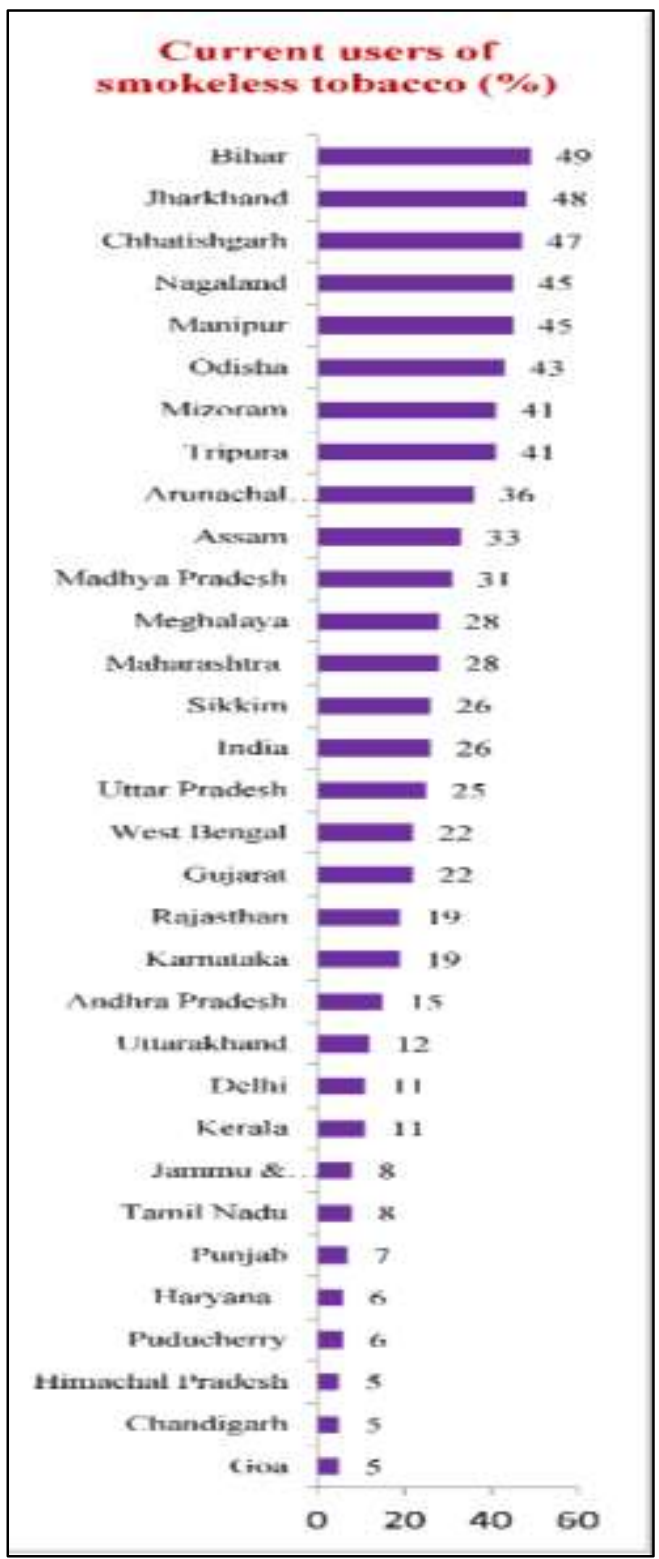

Fig. 1(c): Prevalence smokeless tobacco in India (GATS 2009-10).

The study documented the sex of the person as a significant determinant of quitting smokeless tobacco. The hazard of quitting smokeless tobacco was high among women compared to men (hazard ratio $=1.02, \mathrm{p}<.01$ ). People living in urban areas had 1.21 times higher chances of quitting smokeless tobacco compared to their rural counterparts. Education shows a significant positive association with quitting smokeless tobacco. Compare to uneducated persons, those with secondary education and above were 1.69 times $(\mathrm{p}<.01)$ and those with primary but less than secondary education 1.59 times $(\mathrm{p}<.01)$ more prone to quit smokeless tobacco. Compared with government and non-government employees, the 
probability of quitting smokeless tobacco was higher among students (hazard ratio=2.45) followed by homemakers (hazard ratio=1.34), the retired or unemployed (hazard ratio=1.25) and the self-employed (hazard ratio=1.18). Again, region emerged as a significant factor affecting the chances of quitting smokeless tobacco. People from the south were 1.46 times more likely to quit smokeless tobacco followed by the central region (hazard ratio=1.37) and the north. However, the chances of quitting smokeless tobacco were less in the North-East (hazard ratio $=0.48$ ), followed by the central (hazard ratio=0.94) and western regions (hazard ratio=0.98) compared with people from the northern part of the country.

\section{Pattern of tobacco use}

Results from the Table 1.4, three level multilevel logistic regressions models were used to carry out the pattern and correlates of tobacco use. The state level and PSU level intercept variance in model 1 was 0.34 and 0.20 and in model 2 it was 0.24 and 0.36 both were statistically significant. Expressed as intra-class correlation coefficients, these variances indicate that 14 percent and around 9 percent of the variability in smoking is associated with between-PSU (level 2) and between state (level 3) differences. As usually the case, between-individual differences are far more important. Model 2 incorporates all explanatory variables i.e. individual, PSU and state level, into the model. The odds of smoking was three times higher in 45-64 $(\mathrm{OR}=3.31 * * *)$ age group compared to age group 15-24. Results highlight the positive significant impact of level of education, as education increases tobacco smoking decreases and it was the lowest at the secondary and higher level $\left(\mathrm{OR}=0.33^{* * *}\right)$ in comparison with no formal schooling.

Table 1: Cox proportional hazard ratio of quitting tobacco among smokers and users of smokeless tobacco by selected background characteristics in India, 2009-10.

\begin{tabular}{|c|c|c|c|c|}
\hline Background characteristics & $\begin{array}{l}\text { Hazard ratio of } \\
\text { smokers }\end{array}$ & Standard error & $\begin{array}{c}\text { Hazard ratio of users of } \\
\text { Smokeless }\end{array}$ & Standard error \\
\hline $\begin{array}{l}\text { Sex } \\
\text { Male® }\end{array}$ & & & & \\
\hline $\begin{array}{l}\text { Female } \\
\text { Residence } \\
\text { Rural } \AA\end{array}$ & $1.35^{* * *}$ & 0.001 & $1.02 * * *$ & 0.001 \\
\hline Urban & $0.91^{* * *}$ & 0.000 & $1.21 * * *$ & 0.001 \\
\hline $\begin{array}{l}\text { Education } \\
\text { No formal schooling } ®\end{array}$ & & & & \\
\hline $\begin{array}{l}\text { Less than primary } \\
\text { Primary but less than secondary } \\
\text { Secondary and above }\end{array}$ & $\begin{array}{l}1.01^{\text {*** }} \\
2.02^{* * *} \\
2.43^{\text {*** }}\end{array}$ & $\begin{array}{l}0.000 \\
0.001 \\
0.002\end{array}$ & $\begin{array}{l}1.07 * * * \\
1.59 * * * \\
1.70 * * *\end{array}$ & $\begin{array}{l}0.001 \\
0.001 \\
0.002\end{array}$ \\
\hline $\begin{array}{l}\text { Occupation } \\
\text { Govt. \& non-Govt. employee } ®\end{array}$ & & & & \\
\hline Self employed & $1.12^{* * *}$ & 0.000 & $1.18 * * *$ & 0.001 \\
\hline Student & $0.91^{* * *}$ & 0.006 & $2.50 * * *$ & 0.007 \\
\hline Homemaker & $0.89^{* * *}$ & 0.001 & $1.34 * * *$ & 0.001 \\
\hline Retired or unemployed & $1.44^{* * *}$ & 0.001 & $1.25 * * *$ & 0.001 \\
\hline $\begin{array}{l}\text { Region } \\
\text { North } ®\end{array}$ & & & & \\
\hline Central & $1.24^{* * * *}$ & 0.002 & $1.37 * * *$ & 0.005 \\
\hline East & $1.17^{* * *}$ & 0.002 & $0.94 * * *$ & 0.003 \\
\hline North-East & $0.62^{* * *}$ & 0.002 & $0.48 * * *$ & 0.002 \\
\hline West & $1.07^{* * * *}$ & 0.002 & $0.98 * * *$ & 0.003 \\
\hline South & $1.27^{* * *}$ & 0.002 & $1.46 * * *$ & 0.005 \\
\hline
\end{tabular}

Note: - ${ }^{\circledR}$ Reference category, $* * * \mathrm{P}<0.01$.

Table 2: Log-rank test for equality of survivor functions among the groups of smokers.

\begin{tabular}{llll}
\hline & Chi-square & d.f. & P value \\
\hline Sex & 3046.14 & 1 & 0.00 \\
Residence & 29301.24 & 1 & 0.00 \\
Education & 1362857.5 & 3 & 0.00 \\
Occupation & 211780.85 & 4 & 0.00 \\
Region & 85552.70 & 5 & 0.00 \\
Region & 244328.12 & 5 & 0.00 \\
\hline
\end{tabular}

Table 3: Log-rank test for equality of survivor functions among the groups of users of smokeless.

\begin{tabular}{llll}
\hline value & Chi-square & d.f. & $\mathrm{P}$ \\
\hline Sex & & & \\
Residence & 8814.37 & 1 & 0.00 \\
Education & 106402.48 & 1 & 0.00 \\
Occupation & 374469.13 & 3 & 0.00 \\
Region & 165547.69 & 4 & 0.00 \\
\hline
\end{tabular}


S.K. Singh and G.C. Kashyap(2016) Int. J. Soc. Sci. Manage. Vol-3, issue-1: xxx-xxx

Table 4: Multilevel odds ratio of smoking and use of smokeless tobacco status in India, 2009-10.

\begin{tabular}{|c|c|c|c|c|}
\hline & \multicolumn{2}{|c|}{ Tobacco smokers } & \multicolumn{2}{|c|}{ Users of smokeless tobacco } \\
\hline & Model 1 & Model 2 & Model 1 & Model 2 \\
\hline Intercept (coefficient) & $-1.68 * * *$ & $-.65 * * *$ & $-1.47 * * *$ & $-2.02 * * *$ \\
\hline \multicolumn{5}{|l|}{ Age ofrespondent } \\
\hline \multicolumn{5}{|l|}{$15-24 \AA$} \\
\hline $25-44$ & & $2.30 * * *$ & & $1.70^{* * *}$ \\
\hline $45-64$ & & $3.31 * * *$ & & $1.69^{* * *}$ \\
\hline $65+$ & & $2.86^{* * *}$ & & $1.77 * * *$ \\
\hline \multicolumn{5}{|l|}{ Sex } \\
\hline \multicolumn{5}{|l|}{ Male $®$} \\
\hline Female & & $0.06 * * *$ & & $0.48 * * *$ \\
\hline \multicolumn{5}{|l|}{ Residence } \\
\hline \multicolumn{5}{|l|}{ Rural® } \\
\hline Urban & & $0.87 * * *$ & & $0.48 * * *$ \\
\hline \multicolumn{5}{|l|}{ Education } \\
\hline \multicolumn{5}{|l|}{ No formal schooling® } \\
\hline Less than primary & & $0.78 * * *$ & & 1.02 \\
\hline Primary but less than secondary & & $0.51 * * *$ & & $0.84^{* * *}$ \\
\hline Secondary and above & & $0.33 * * *$ & & $0.51 * * *$ \\
\hline \multicolumn{5}{|l|}{ Occupation } \\
\hline \multicolumn{5}{|l|}{ Govt. \& non-Govt. employee ® } \\
\hline Self employed & & $0.91 * * *$ & & $0.89 * * *$ \\
\hline Student & & $0.35^{* * *}$ & & $0.33^{* * *}$ \\
\hline Homemaker & & $0.71 * * *$ & & $0.66^{* * *}$ \\
\hline Retired or unemployed & & $0.79 * * *$ & & $0.76^{* * *}$ \\
\hline \multicolumn{5}{|l|}{ Standard of Living Index } \\
\hline \multicolumn{5}{|l|}{ Low ${ }^{\circledR}$} \\
\hline Medium & & 0.99 & & 0.96 \\
\hline High & & $0.85^{* * *}$ & & $0.70 * * *$ \\
\hline \multicolumn{5}{|l|}{ Region } \\
\hline \multicolumn{5}{|l|}{ North ${ }^{\circledR}$} \\
\hline Central & & 0.75 & & $5.20 * * *$ \\
\hline East & & $0.54 * *$ & & $8.18 * * *$ \\
\hline North-East & & $2.29 * * *$ & & $8.75^{* * *}$ \\
\hline West & & $0.31 * * *$ & & $2.49 * * *$ \\
\hline South & & $0.62 * *$ & & 1.42 \\
\hline \multicolumn{5}{|l|}{ Random Part } \\
\hline State variance & $0.34 * *$ & $0.24 * *$ & $1.11^{* *}$ & $0.22 * *$ \\
\hline PSU variance & $0.20 * *$ & $0.36^{* *}$ & $0.43 * *$ & $0.40 * *$ \\
\hline
\end{tabular}
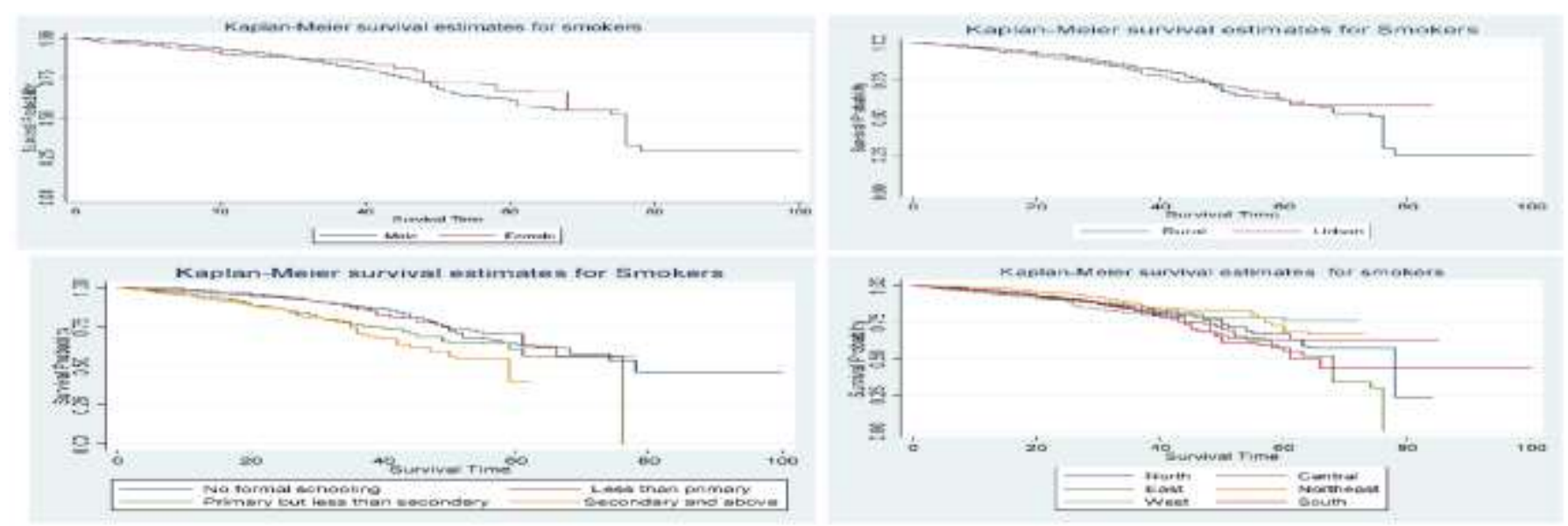

Fig. 2: Kaplan meier survival estimates of smokers by selected background characteristics. 

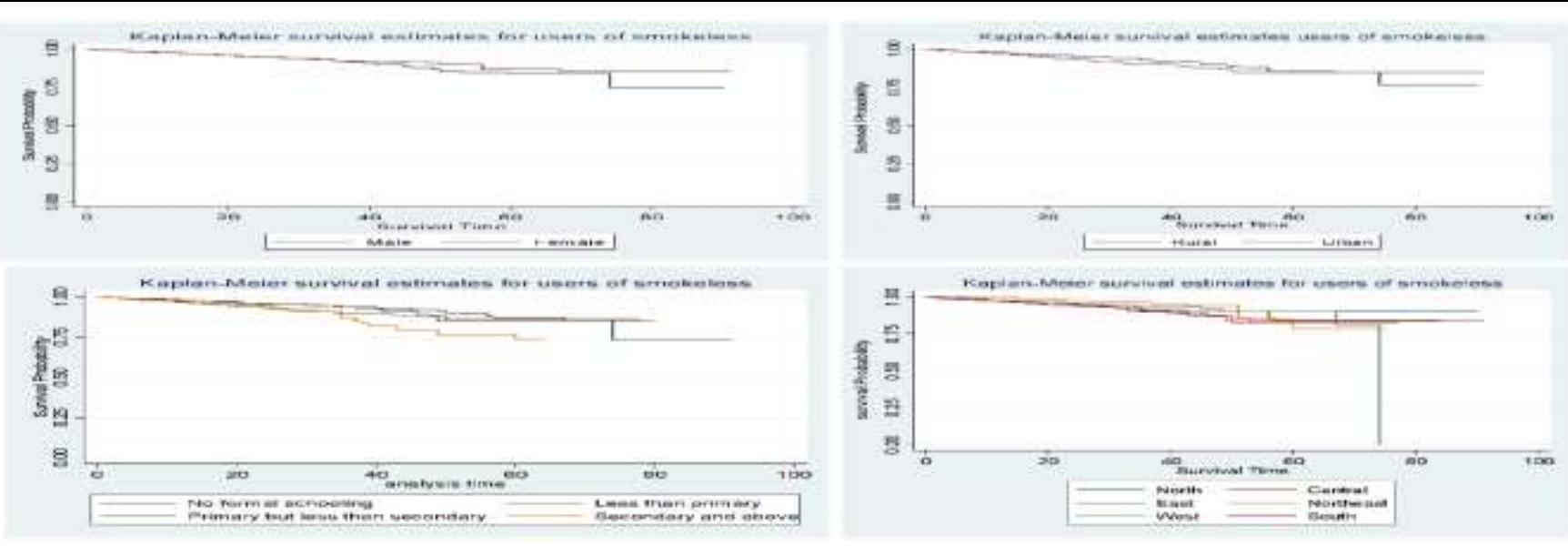

Fig. 3: Kaplan meier survival estimates of users of smokeless by selected background characteristics.

The prevalence of tobacco use was the highest in Northeast region $(\mathrm{OR}=2.29 * * *)$ in comparison of northern region. Among the users of smokeless tobacco the state level and PSU level intercept variance in model 1 was 1.11 and 0.43 and in model 2 it was 0.22 and 0.40 both were statistically significant. The variable age of respondent had the fewer variation in use of smokeless tobacco among the age group 25-44, 45-64 and 65+ in comparison to age group $15-24(\mathrm{OR}=1.7 * * * *)$ that confirmed the consistent use of smokeless tobacco after the 24 years. Females from urban area were 51 percent less likely to use smokeless tobacco. Regional variation pointed out North-eastern $\left(\mathrm{OR}=8.75^{* * *}\right)$, Eastern $\left(\mathrm{OR}=8.18^{* * *}\right)$, Central region $\left(\mathrm{OR}=5.11^{* * *}\right)$, Western $(\mathrm{OR}=2.49 * * *)$ and Southern region $(\mathrm{OR}=1.42 * * *)$ are more likely to use of smokeless tobacco in comparison of Northern region. This analysis highlight that the factors like educational attainment, standard of living and regions are strongly associated with smoking and as well as use of smokeless tobacco.

\section{Discussion}

The current appearance of epidemiological transition in India lies in the shift from communicable diseases to noncommunicable and lifestyle based diseases accounting for the major disease burden. Recent estimates portray that deaths due to non-communicable diseases constitute about 42 percent of all the deaths in India compared to 38 percent of deaths due to communicable disease. Tobacco smoking and use of smokeless tobacco have been widespread for many decades among men in India, and have been responsible for most adult deaths involving cardiovascular disease, hypertension, and stroke, different forms of cancer, tuberculosis, other respiratory diseases and diseases related to the liver [18]. The findings from our study shows that the highest percentage of young people currently using tobacco product in the Northeastern states of India. The prevalence of tobacco use is the highest in Mizoram (63\%) followed by four other states from the North-Eastern region, that is, Nagaland (57\%), Tripura (56\%), Meghalaya (55\%) and Manipur (54\%). Our concern is that, since the childhood age the children start using tobacco, and the more likely are they to become addicted, and tobacco consumption become the important things in any one's life in North-east, possible reasons may be cultural issues, living environment, parental use of tobacco. The need is more common among cigarette smokers and users of smokeless tobacco. This shows that children were already developing dependency on tobacco, they start consuming tobacco products at very young age. Many other factor may be working that showed strong association with tobacco use: parental and closest friends' tobacco use; lack of knowledge on harmful effects of tobacco; positive attitude towards tobacco use by others; and viewing of tobacco advertisements. Apart from the above states, the other three states from the NorthEastern region also rank very high in the chronology and thus all the seven sister states from the region portray the highest tobacco smoking in the country. Of course, there are many other states where tobacco smoking is higher than the national average. The highest prevalence of theuse of smokeless tobacco is reported in some EAG states like Bihar(49\%), Jharkhand (48\%), Chhattisgarh (47\%) and in the North-Eastern states of Nagaland (45\%) and Manipur (45\%), while the lowest prevalence is reported by the states of Himachal Pradesh, Goa, Chandigarh $(5 \%$ in each).

The results from the Kaplan Meier Survival estimates pointed out that the probability of quitting is higher among women than among men and that it is relatively higher in urban areas as compared to rural areas, both for smokers as well as users of smokeless tobacco. There has been profound regional variation, where the probability of quitting is the highest in the southern states both among smokers as well as users of smokeless tobacco. Further, the Cox proportion hazard ratio, which portrays the cumulative probability of quitting tobacco use, has been computed for major socioeconomic groups relevant for planning and intervention of tobacco control programs. Three level multilevel logistic regressions models portrays the pattern and correlates of tobacco use. The odds of Smoking higher in 45-64 age group compare to age group 15-24. The variable age of respondent had the fewer 
variation in use of smokeless tobacco among the age group 25-44, 45-64 and 65+ in contrast to age group 15-24 that confirmed the consistent use of smokeless tobacco after the 24 years. Female belongs to urban area were 51 percent less likely to use smokeless tobacco. This study concluded that the factors like educational attainment, standard of living and regions were associated with smoking and as well as use of smokeless tobacco.

\section{Conclusions}

Tobacco use is growing fastest in the low-income countries due to steady population growth coupled with tobacco industry targeting and ensuring that millions of people become fatally addicted each year. As results portrays about the prevalence of tobacco smoking is the highest in North-eastern state and smokeless user were the highest in EAG states of India. Continuation of tobacco consumption up to older ages reduces the age of tobacco users, due to initiation in early age, that maximizes duration of tobacco consumption. So for initiation in early ages also a danger sign for the health of teen agers and youngsters. At the same time, the chances of quitting tobacco is very low in any setting in Indian. So that enormous consumption of tobacco use leads to disease asthma, tuberculosis, cancer etc. Auspiciously, life expectancy of male and female in India has increased but people are living their lives with diseases and disability that can be linked with tobacco consumption. Tobacco consumption should be minimized by the explaining the facts about the health risks from smoking as well as use of smokeless tobacco, ban on smoking in public places and workplaces, comprehensive bans on advertising and promotion. Although, increasing tobacco prices may be the single most effective way to reduce tobacco consumption in India.

\section{Recommendation}

In view of the disproportionally high rate of smoking and use of smokeless tobacco in the North-Eastern states along with the progression of the tobacco epidemic, there is an urgent need of innovative strategies to strengthen cessation efforts in North-eastern states. Print as well as electronic media have to play a proactive role in creating awareness among the most vulnerable groups, especially among youth and women, so that they can be convinced to quit and the tobacco related disease burden can be minimized. In view of the existing epidemiology transition and significant link between tobacco use and health hazard, the Government should effectively strengthen programmes and interventions targeting young people need to expand their focus to include both preventing initiation as well as offering youth cessation programmes.

\section{Authors Contribution}

Conceived and designed the experiments: SKS GCK. Performed the experiments: SKS GCK. Analyzed the data:
SKS GCK. Contributed reagents/materials/analysis tools: SKS GCK. Wrote the paper: SKS GCK.

\section{Acknowledgement}

Authors are thankful to International Institute for the Population Sciences (IIPS), Govandi Station Road Deonar Mumbai for providing us a GATS India (2009-10) data for this research work.

\section{References}

Bansal R, John S and Ling PM (2005) Cigarette advertising in Mumbai, India: targeting different socioeconomic groups, women, and youth. Tobacco Control; 14:201-206. DOI: 10.1136/tc.2004.010173.

Brenda G (2006) Checking Assumptions in the Cox Proportional Hazards Regression Model. Centre for Statistical Consultation and Research, University of Michigan.

Chadda RK and Sengupta SN (2002) Tobacco use by Indian adolescents. Tobacco Induced Diseases Vol. 1, No. 2: $111-119$

Colby SM, Tiffany ST, Shiffman S and Niaura RS (2000) Are adolescent smokers dependent on nicotine? A review of the evidence. Drug and Alcohol Dependence; 59: S83S95.

Enis B, Brigden LW and Prindiville J(2000) Research priorities for tobacco control in developing countries: a regional approach to a global consultative process Source: Tobacco Control, Vol. 9, No. 2 pp. 217-223. Ottawa, Ontario, Canada.

GATS. Global Adult Tobacco Survey (2009-10) International Institute for Population Sciences (IIPS), Mumbai, India The Ministry of Health and Family Welfare $(M O H F W)$, Government of India.

Gavarasana S, Gorty PV and Allam A (1992) Illiteracy, ignorance and willingness to quit smoking among villagers in India. Japanese Journal of Cancer Research; 83: $340-343$

Gupta PC (1996) Survey of sociodemographic characteristics of tobacco use among 99598 individuals in Bombay, India using handheld computers. Tobacco Control; 5: 114-120.

Hosmer DW, Lemeshow S and MayS (1999)Applied Survival Analysis. Wiley, New York.

Jayant K, Notani PN, Gulati SS and Gadre VV (1991) Tobacco use in school children in Bombay, India. A study of knowledge, attitude and practice. Indian Journal of Cancer; 28: 139-147.

Jha P, ChaloupkaFJ and Corrao M (2006) Reducing the burden of smoking world-wide: effectiveness of Interventions and their Coverage. Drug and Alcohol Review, 25, $597-$ 609.

Jha P, Jacob B and Gajalakshmi V (2008) A nationally representative case-control study of smoking and death in India. N. Engl. J. Med., 358, 1137-1147. 
John F (2008) Cox Proportional-Hazards Regression for Survival Data. Appendix to an $\mathrm{R}$ and S-PLUS Companion to Applied Regression.

Kapoor SK, Anand K and Kumar G (1995) Prevalence of tobacco use among school and college going adolescents of Haryana. Indian Journal of Pediatrics; 62: 461-466.

Lal PG, Wilson NC and Gupta PC (2012) Attributable deaths from smoking in the last 100 years in India. Research Communications, Current Science, Vol. 103, No. 9.

Lal PG, Wilson NC and Gupta PC (2012) Attributable deaths from smoking in the last 100 years in India. Research Communications, Current Science, Vol. 103, No. 9.

Mamatha M and Rao VN (2014) Use of Tobacco in India and the Influencing Factors: An Analysis on National Family and Health Survey Data (NFHS-III). International Journal of Computer Science and Information Technologies, Vol. 5 (2), 1664-1667.

Merete O (2001) Revives. British Medical Journal, April 7, Vol. 322, No. 7290, p. 869.

Patel DR (1999) Smoking and children. Indian Journal of Pediatrics; 66: 817-824.

Rani M, Bonu S and Jha P (2003) Tobacco use in India: prevalence and predictors of smoking and chewing in a national cross sectional household survey. Tobacco

Control. 12(4):

(http://www.tobaccocontrol.com/cgi/content/full/12/4/e4)

Reddy SK and Gupta PC (2004)Report on Tobacco Control in India. Ministry of Health and Family Welfare (MOHFW), Government of India, New Delhi.

Sarma PV, Dhand R, Malhotra A, Malhotra S and Sharma BK (1990) Pattern of smoking in north Indian adults. Indian Journal of Chest Diseases and Allied Sciences 32: 83-93.

Shibuya K, Ciecierski C and Guindon E (2003) WHO Framework Convention on Tobacco Control: development of an evidence based global public health treaty. British Medical Journal 327: 154-157.

Vendhan G and Peto R (2003) Smoking and mortality from Tuberculosis and other diseases in India. The Lancet: $\mathrm{Vol}$ 362: 507-515.

Warren CW, Riley L, Asma S, Eriksen MP, Green L, Blanton C, Loo C, Batchelor S and Yach D (2000) Tobacco use in youth: a surveillance report from the Global Youth Tobacco Survey Project. Bulletin of World Health Organization 78: 868-876. 